
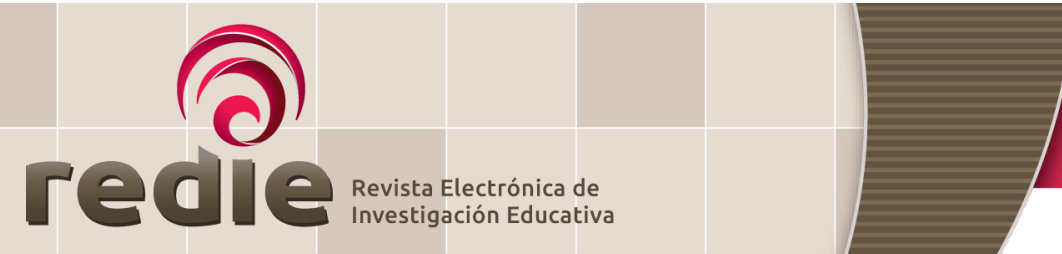

\title{
Herramental pragmático para el dictado de clases sincrónicas en modalidad remota
}

Andrés Cuesta González (*) https://orcid.orq/0000-0003-3388-7878

(*) Universidad Argentina de la Empresa

Cómo citar: Cuesta, A. (2021). Herramental pragmático para el dictado de clases sincrónicas en modalidad remota. Revista Electrónica de Investigación Educativa, 23, e2r, 1-3. https://doi.org/10.24320/redie.2021.23.e2r.4474

Levy, D. (2020). Teaching effectively with zoom. A practical guide to engage your students and help them learn. Amazon, 198 pp.

La irrupción de la pandemia por COVID-19 obligó a una migración acelerada de la educación presencial a una modalidad remota para asegurar la continuidad académica. No se trató de una opción planificada sino forzada por el contexto, a fin de mantener las actividades de docencia durante el período de confinamiento, también denominado en algunos países latinoamericanos como "aislamiento social preventivo y obligatorio". Justamente estas características nos obligan a diferenciar con claridad la emergencia de este modelo de enseñanza remota (para dar una respuesta urgente a la demanda social de continuidad formativa) de las experiencias de aprendizaje virtual, bien planificadas y desarrolladas. Sin embargo, fue la educación remota la que brindó la posibilidad de asegurar la continuidad académica en los diferentes niveles educativos, especialmente en el nivel superior.

Partiendo de esta situación, Dan Levy publicó a principios de julio de 2020 un libro orientado a brindar consejos concretos y elementos de reflexión sobre la práctica docente desarrollada en clases sincrónicas a través de la plataforma Zoom. Levy es miembro del claustro docente de la Harvard Kennedy School, especializado en políticas públicas, con más de 15 años de experiencia como profesor de dicha Universidad. Su nuevo libro, publicado con gran sentido de oportunidad, parte de reflexiones sobre la propia práctica docente, los intercambios con otros colegas y entrevistas a estudiantes universitarios que vivieron la experiencia de clases virtuales por primera vez.

Si bien el libro se centra en las posibilidades que brinda la plataforma Zoom en particular, la mayoría de sus propuestas son aplicables a muchas otras plataformas similares de videoconferencias. El libro articula a través de sus capítulos ciertos presupuestos básicos de orden pedagógico con caminos prácticos para promover la participación y compromiso de los estudiantes con su aprendizaje, enriquecer los componentes expositivos de la secuencia didáctica e integrar la dimensión sincrónica con el ecosistema mucho más amplio de la formación on line.

La primera parte del texto (Ideas clave, pp. 15-40), señala inicialmente que resulta relevante y pertinente tener en cuenta que la migración de la clase presencial a la modalidad remota supone ciertas pérdidas. En este sentido, considera importante identificar esas pérdidas: la clase presencial brindaría mayor riqueza en la articulación de la comunicación verbal y no verbal, permitiría identificar más fácilmente los estados de ánimo de los estudiantes, etc. Por eso mismo el autor considera que resulta clave conocer qué ventajas que constituyen características propias de la clase presencial se pierden con la nueva modalidad, para luego aprovechar mejor las nuevas oportunidades que brindan las clases remotas. También resalta que los docentes no deben perder de vista que lo verdaderamente importante sigue siendo el aprendizaje de 
los estudiantes y que las plataformas para la realización de clases sincrónicas son sólo el vehículo para alcanzar ese objetivo. Es vital tener siempre presente que la tecnología no es nunca un objetivo en sí mismo, sino un medio para alcanzar un fin: el aprendizaje.

En ese marco de pensamiento, Levy avanza sobre los principios pedagógicos que subyacen en las que considera buenas prácticas docentes, para poder aplicarlos luego al diseño y desarrollo de las clases sincrónicas. Desde la perspectiva del autor, los principios que considera deben guiar la práctica docente en la modalidad remota son cinco: centrarse en el estudiante, planificar un aprendizaje activo (de manera que no se trate sólo de un mero proceso transmisivo), empezar la clase teniendo en mente cómo se pretende terminarla (en definitiva planificar), aprovechar las ventajas que tiene la enseñanza on line (que si bien supone pérdidas, también ofrece nuevas oportunidades) y no olvidar que los docentes se hacen a través de la práctica, motivo por el cual a medida que se prueban nuevos recursos y se les ejercita, la experiencia permite mejorar.

En la segunda parte del libro (pp. 41-112) se proponen diversos caminos orientados a promover la participación y el compromiso de los estudiantes en las clases sincrónicas, que el autor destaca por su variedad y utilidad. Entre esos caminos desarrolla alternativas para ceder la palabra a los estudiantes utilizando herramientas para ordenar la participación; realizar consultas, encuestas o quizzes breves durante la clase; promover el uso del chat, introduciendo la escritura como vehículo de participación; trabajar en grupos pequeños (que en Zoom se suelen denominar salas); poner en común trabajos o resultados de las actividades de los estudiantes (habilitando que los mismos alumnos puedan compartir sus pantallas).

El autor advierte que es importante tener en cuenta durante la planificación que las conversaciones en las clases remotas tienden a llevar más tiempo que en una clase presencial. También resalta que las herramientas para realizar consultas y encuestas pueden ser muy útiles para despertar interés en los estudiantes, así como para monitorear cómo están aprendiendo y al mismo tiempo para enseñar de una manera más flexible. En cuanto al chat, lo considera una manera rápida y eficiente para conocer qué están teniendo en mente los estudiantes en un determinado momento, pero para que su uso sea adecuado propone establecer normas compartidas con anticipación. En cuanto a la división del curso en grupos de menor tamaño para realizar diversas actividades, considera que se trata de una práctica muy valiosa, pero que requiere que el docente sea muy claro con la tarea a desarrollar y el tiempo del que los estudiantes dispondrán para generar el entregable que se solicita. También sugiere que en un momento del intercambio sincrónico al menos algunos de los alumnos presenten en la sesión plenaria el trabajo que generaron de manera individual o bien en los pequeños grupos de los cuales participaron (según el tipo de actividad pautada). Según Levy, también se requiere aquí de consignas claras y bien planificadas para que este tipo de participación sea fructífera.

En la tercera parte del libro (pp. 113-147), el autor brinda una serie de sugerencias orientadas al docente en los momentos expositivos de las clases sincrónicas. Brinda explicaciones operativas sobre la forma de presentar diapositivas, videos, sitios web y otros tipos de recursos, pero advierte que presentar diapositivas por un largo período de tiempo sin involucrar a los estudiantes en su propio aprendizaje puede ser poco efectivo. Por eso sugiere planificar algún tipo de interacción cada pocos minutos de clase expositiva. Al respecto, señala que es necesario tener en cuenta que cuando se comparten diapositivas éstas ocupan gran parte de la pantalla y también de la atención de los estudiantes. Por eso resulta conveniente dejar de compartirlas en los segmentos en los que realmente no se necesitan, a fin de generar otro tipo de interacción (más cercana) con los estudiantes. El autor sostiene que, mientras se presentan diapositivas, lo ideal es que el docente mantenga la vista en los estudiantes más que en los slides. En tal sentido, destaca que si se tiene acceso a un segundo monitor este objetivo es mucho más fácil de alcanzar.

Levy sugiere también realizar anotaciones para explicar conceptos o para dejar registro de los comentarios/participaciones de los estudiantes, a fin de volver la clase más dinámica y efectiva. Al respecto explica que, de acuerdo con las preferencias de cada docente y los dispositivos de los que disponga, se puede optar entre realizar anotaciones manualmente o mediante el teclado. De alguna 
manera este recurso se erige como un sustituto de la clásica pizarra o pizarrón. Por último, sugiere pretestear las herramientas que se usarán en clase con colegas, con el objetivo de realizar ajustes antes de utilizarlas. De esta manera cualquier problema podrá ser resuelto antes de que la clase tenga lugar.

En la cuarta y última parte (148-190), el autor avanza hacia una perspectiva integradora. Resalta en primera instancia que es necesario tener en cuenta que las clases sincrónicas son sólo una parte del "ecosistema" (mucho más amplio) que involucra la enseñanza on line. Básicamente, indica, las actividades de los estudiantes pueden clasificarse en dos grandes tipos. Por un lado identifica las clases sincrónicas: todos los alumnos desarrollando actividades juntos, en un mismo momento, en el marco de una clase en vivo, vía Zoom o cualquier otra plataforma (por ejemplo Jitsi, que es un software libre y de código abierto, Meet de Google, Teams de MS, etc.). Y por otro lado están las actividades asincrónicas donde los estudiantes acceden a materiales de acuerdo con su disponibilidad de tiempo, cada uno en el momento en que prefiere. Esta clasificación supone dos decisiones clave según Levy: en primer lugar, es necesario determinar qué materiales serán utilizados en las clases sincrónicas y cuáles se dejarán para el trabajo asincrónico de los estudiantes; en segundo lugar resulta clave determinar cómo se apalancará el aprendizaje y trabajo asincrónico de los alumnos a través de las sesiones sincrónicas (en vivo), para que los materiales asincrónicos sean luego mejor aprovechados por los alumnos durante su período de trabajo autónomo. Finalmente, el autor destaca la importancia de la construcción de una comunidad de aprendizaje en las experiencias de educación remota. Pero advierte la necesidad de tomar conciencia en que alcanzar este objetivo requiere de un mayor y deliberado esfuerzo que en la educación presencial. Por eso mismo recomienda pensar caminos para construir una comunidad de aprendizaje antes, durante y fuera de la clase.

El libro también brinda acceso a un sitio de Internet que cuenta con diversos materiales para descargar, consejos operativos adicionales, listas de chequeo útiles para verificar la preparación de clases y, lo que resulta aún más valioso e interesante, la posibilidad de reflexionar sobre la propia práctica y sumar nuevos materiales de manera colaborativa entre los lectores.

En términos generales, podría señalarse que si bien ya en la introducción el autor plantea la importancia de contextualizar sus recomendaciones y sugerencias, señalando múltiples diferencias que inciden en las posibilidades de la docencia sincrónica remota, se trata de una problemática que hubiera requerido mayor desarrollo teniendo en cuenta las importantes brechas de acceso que existen en relación tanto con el equipamiento como con la conectividad de estudiantes y docentes. Por otra parte, podría valorarse la publicación como excesivamente instrumental por las múltiples recomendaciones específicas y puntuales que ofrece para el ejercicio de la docencia sincrónica a partir de una plataforma particular de videoconferencias, sin ahondar demasiado en los fundamentos didácticos y pedagógicos sobre los cuales se asientan dichos consejos, excepto en una breve introducción inicial. Sin embargo ese es justamente el objetivo de la publicación y allí radica su principal aporte, que es útil y valioso en tanto sistematiza una variedad de cuestiones prácticas sin obturar la práctica con respuestas únicas o "recetas" cerradas, sino con sugerencias concretas que luego requieren ser adaptadas a contextos diversos de aprendizaje y estilos particulares de enseñanza. 